\title{
Late-preterm infants, a growing challenge in both the short and long term
}

Over the past decades, noticeable changes have occurred in care provided at neonatal intensive care units (NICUs), which have been progressively incorporated into everyday practice and are accompanied by relentless technological advances. This has led to major modifications, both in diagnosis and treatments, which have gradually helped to change outcomes. Many of these changes translated into important benefits, some resulted in no advances, and others caused direct or indirect harmful effects in the short and long term.

Here I will discuss changes related to preterm infants born only a few weeks before the late stages of pregnancy; a situation that has called the attention in the fields of perinatal care and pediatrics, and that has been addressed in numerous publications in recent years.

These newborn infants were first called "latepreterm" in 2006, as proposed by the National Institute of Child Health and Human Development in the United States to replace the previous preterm descriptor "near-term infants". The reason for this change was that the previous classification would lead obstetricians, especially, to believe that there were very few differences as regards maturation, mortality and morbidity between these infants and term infants. These newborn infants usually weigh $2500 \mathrm{~g}$ or more, so their appearance may be similar to that of those born at term. Considering that birth weight is more important than maturation is a glaring and serious mistake that has caused, and continues to cause, multiple damages, because doing so leaves out the fact that neonatal maturation continues until week 41 . Certainly, and for some reason, human nature has determined that a normal pregnancy should last 40 weeks, with little variation (39-41 weeks). Any other gestation duration may have adverse results, not only at birth but also for life.

Unfortunately, although the change in classification was correct and well-meaning, it did not result in perinatal care improvements; on the contrary, harmful consequences in neonatal and infant health have increased.

The most widely accepted definition of latepreterm infants refers to those born between 34 and 36 completed weeks of gestation. A perfect example of the impact of this situation is that almost $80 \%$ of preterm births are late-preterm, and its incidence has increased by $25 \%$ between 1990 and 2006. In the United States, 500000 births occur before 37 weeks of gestation every year, and approximately 400000 of these are late-preterm births and account for 8-9\% of all births.

Among harmful effects caused by changes in perinatal care, it is worth noting that the rate of preterm births has increased over the past 25 years, even in developed countries. This is mostly associated with the marked increase in multiple pregnancies as a result of medicallyassisted fertilization and the noticeable increase in the number of $\mathrm{C}$-sections and labor induction between 34 and 36 weeks of gestation. ${ }^{1}$ Medicallyassisted fertilization techniques have been a great advance but, like many other advances, they have also resulted in serious problems due to the remarkable increase in multiple pregnancies. In the United States, the rate of twin pregnancies in 2006 was $32 \%$, approximately three times higher than their natural incidence, and between 1972 and 1999 , triplet pregnancies increased by $600 \%$, and quadruplet pregnancies, by $1200 \%$. In addition, $50 \%$ of twin pregnancies and $43 \%$ of triplet pregnancies result in late preterm births. In 2010 at Hospital Italiano de Buenos Aires, the following rates were observed: twin pregnancies: $31.2 \%$ (three times higher than the natural rate), triplet pregnancies: $2.8 \%$ (eight times higher than the natural rate), quadruplet pregnancies: 1.2\% (12 times higher than the natural rate). Another aspect of medically-assisted fertilization is that the rate of mothers older than 44 years old is 50 times higher, therefore increasing perinatal morbidity and health care costs, both during pregnancy and at neonatal care units.

The remarkable growth in the number of medically-unnecessary C-sections is probably the main reason for the increase in late-preterm births. In the United States, between 1990 and 2006, the rate of medically-unnecessary C-sections increased by $46 \%$. At present, the rate of these procedures in many private facilities in our setting is $70 \%$ or higher.

Late-preterm infants give rise to varying problems, either in relation to their higher mortality and morbidity, both neonatal or longterm, or the impact on parents and their suffering, and the high costs of care provided at the NICU and during their follow-up. 
Multiple studies have described a higher neonatal mortality in infants born between 34 and 36.6 weeks of gestation in comparison with term infants. The results of a study conducted in the United States between 1995 and 2002 show that early mortality (0 to 6 days of life), late mortality ( 7 to 27 days of life) and post-natal mortality (28 to 364 days of life) were six, three and two times higher in late-preterm infants than in those born at term. ${ }^{2}$

In relation to neonatal morbidity, an observation made in an extensive population indicated that it was 20, 10 and 5 times higher at 34,35 and 36 weeks, respectively, than at 40 weeks. ${ }^{3}$ Respiratory disorders are, by far, the most common reason of neonatal morbidity, followed by jaundice and late-onset sepsis. One study observed that the rate of elective $\mathrm{C}$-section doubled in the study period, both in term and late-preterm infants; in this group, compared to infants born vaginally, neonatal morbidity was twice as high, respiratory depression at birth was 70\% higher, and admission to the NICU was somewhat more than twice as high. ${ }^{4}$

Other data are also extremely important. Neonatal morbidity at 37 weeks was $6 \%$, more than twice as high than at 40 weeks. ${ }^{5}$ This highlights the grounded concept that, undoubtedly, perinatal risk is lower when birth occurs between 39 and 41 weeks of gestation, not between 37 and 38 weeks, even though the latter is considered within term (called "early term" birth). Unfortunately, this is not usually taken into consideration by most obstetricians and many neonatologists.

Following discharge, late-preterm infants have three times more chances of being re-hospitalized in the first six months, and approximately $15 \%$ are re-hospitalized in their first year of life.

Long-term morbidity is, at present, an extremely concerning aspect because an immature central nervous system may result in major, even serious, morbidities many years later. Several studies observed the course of children born latepreterm; results indicate that they have a greater risk of developmental disabilities, academic failure, behavioral problems, various diseases, social disorders, and death. ${ }^{6}$ Investigations conducted with follow-up even into adulthood show a higher risk of neurological disabilities (mental retardation, cerebral palsy), and difficulties in school because these individuals have a poorer academic performance and low results in neurocognitive tests.

A recent population-based study assessed more than 6000 children at 7 years old and found that, following adjustment of confounding outcome measures, late-preterm infants showed a significant increase in poor academic achievements, and $25 \%$ had multiple deficits in their academic performance. ${ }^{7}$ In addition, evidence shows that the impact of maturation also affects term infants. A study with data on 128050 singleton births between 37 and 41 weeks of gestation assessed, at the age of 8 , the differences in reading and/ or math ability in relation to gestational age. Achievement scores for children born at 37 and 38 weeks were significantly lower than those for children born at 39,40 or 41 weeks. ${ }^{8}$

Over the last weeks of gestation, there is a remarkable brain development. At 34 weeks, the brain weighs only $60 \%$ of the weight it reaches at 41 weeks, and its volume increases five times. ${ }^{6}$ One study assessed 18-year-old conscripts born late-preterm. Their mean score in intelligence tests was lower than that of those born between 39 and 41 weeks. Another important study assessed adults who were 60 or more years old; those born late-preterm had poorer results in all neurocognitive tests. ${ }^{9}$

Reflecting on what we have described here and its impact both in the short and long term, we may state that the main reason for the remarkable increase in the number of late-preterm infants is related to medical practice. Data from different studies show that the most common factors associated with birth between 34 and 36 weeks are the excessive use of inadequate techniques of medically-assisted fertilization, labor induction and an increased number of C-sections. Most mothers of late-preterm infants have no morbidities, as observed in a study conducted on more than 26000 infants born between 34 and 36 weeks, where $80 \%$ of mothers had no health disorders. ${ }^{3}$

Finally, it is regrettable that most late-preterm births are the result of a reprehensible human behavior, and that this "epidemic" will only change if the basic ethical principles of our profession are respected. As long as such behavior is not modified, no reduction will be observed in the high risks suffered by these children at birth and, probably, for the rest of their lives.

Jose M. Ceriani Cernadas, M.D. Editor

http:/ /dx.doi.org/10.5546/aap.2015.eng.482

1. Janvier A,Spelke B, Barrington KJ. Theepidemic of multiple gestations and neonatal intensive care unit use: the cost of irresponsibility. J Pediatr 2011;159(3):409-13. 
2. TomashekKM,Shapiro-Mendoza CK, Davidoff MJ,Petrini JR. Differences in mortality between late-preterm and term singleton infants in the United States, 1995-2002. J Pediatr 2007;151(5):450-6.

3. Shapiro-Mendoza CK, Tomashek KM, Kotelchuck M, Barfield W, et al. Effect of late-preterm birth and maternal medical conditions on newborn morbidity risk. Pediatrics 2008;121(2):e223-32.

4. De Luca R, Boulvain M, Irion O, Berner M, et al. Incidence of early neonatal mortality and morbidity after late-preterm and term cesarean delivery. Pediatrics 2009;123(6):e1064-71.

5. Gouyon JB, Vintejoux A, Sagot P, Burguet A, et al. Neonatal outcome associated with singleton birth at 34-41 weeks of gestation. Int J Epidemiol 2010;39(3):769-76.
6. Vohr B. Long-term outcomes of moderately preterm, late preterm, and early term infants. Clin Perinatol 2013;40(4):739-51.

7. Chan E, Quigley MA. School performance at age 7 years in late preterm and early term birth: a cohort study. Arch Dis Child Fetal Neonatal Ed 2014;99(6):F451-7.

8. Noble KG, Fifer WP, Rauh VA, Nomura Y, et al. Academic achievement varies with gestational age among children born at term. Pediatrics 2012;130(2):e257-64.

9. HeinonenK,ErikssonJG,LahtiJ,KajantieE, etal.Latepreterm birth and neurocognitive performance in late adulthood: a birth cohort study. Pediatrics 2015;135(4):e818-25.

\section{Electronic publishing brings good news to Archivos Argentinos de Pediatría}

Archivos Argentinos de Pediatría (AAP) has been published continuously for 85 years and has been distributed among pediatricians in the traditional paper format. In 1998 the Sociedad Argentina de $\mathrm{f}$ Pediatría (SAP) website was launched and started offering AAP in electronic format to provide another way of univocal access to its articles.

Such transcendental decision was a turning point in the history of our journal with the origin of a new online era emerging as a supplement of the traditional paper format. Undoubtedly, electronic publishing opened the doors of AAP to the world, followed by a most important milestone: its admission to Medline in 2008. In addition, in recent years, the electronic publication has allowed us to provide other services. Hence, sections, exclusively available online, have been developed, given their characteristics and temporary nature, allowing a different kind of interaction and also providing faster access than paper publications. This isreflected in the access to articles published in advance in "First Online" or the chance of watching videos or taking polls online. We have also entered the world of social networks like Twitter and Facebook ${ }^{1}$ to reach readers using other sources of dissemination of information besides SAP's website and to take advantage of the benefits of viral content distribution using social networks among colleagues. In addition, this has allowed us to have professional presence and reach a different audience who was unaware of AAP or had no access to it. ${ }^{2}$

In line with this, AAP has now launched two new services available to our readers. First of all, we have created a section called "Collections" that offers access to AAP articles on specific topics or fields. The opening collection is on Bioethics, an essential topic. The idea is based on an excellent initiative of the Clinical Ethics Subcommittee of SAP. Its members undertook a hard task of selecting a full series of articles on bioethics published in AAP since 1998. Articles related to philosophy, anthropology, research and even some articles on health policies have been included. Subcommittee members reviewed the selected articles and ended up with a collection of 120 articles organized by date and plan to update it as new articles that meet the collection criteria are published. They have also arranged articles by subtopics: macro-, micro-, and meso-ethics. We hope that this collection facilitates access to specific information so that readers do not need to browse AAP's entire content. It is worth noting that this collection is the result of an expert panel's view and thanks to their knowledge in this field, it may speed up access to those who are novice on an issue or who have less advanced knowledge in a certain topic but wish to approach it in more depth.

Secondly, we are launching another project that will also be a major landmark for AAP. The Publication Council, supported by the Steering Committee, has decided, after 17 years, to offer issues of AAP published before 1998 in electronic format. During the first stage of this process, all issues published between 1990 and 1997 were digitalized and included in the "Previous Issues" section. Therefore, at present, we have a repository of pediatric scientific activities that encompasses the past 25 years. Certainly, this initiative will be helpful to those who want 
access to AAP contents that to date were only in paper format. The objective of this project is to progressively continue turning previous issues into electronic publications. We hope these efforts help to maintain our journal as a publication that offers qualified and interesting contents. This will allow all our readers to access available topics through a quick search of major publications from many years ago and that will be useful for pediatricians and other child and adolescent health care providers in everyday practice.

Paula Otero, M.D. Assistant Editor http:/ /dx.doi.org/10.5546/aap.2015.eng.484

1. Otero P. El desafío de las publicaciones científicas... cómo seguir siendo elegidas por los lectores. Arch Argent Pediatr 2012;110(5):370-1.

2. Rioth MJ, Osterman TJ, Warner JL. Advances in website information resources to aid in clinical practice. $\mathrm{Am} \mathrm{Soc}$ Clin Oncol Educ Book 2015;35:e608-15. 